\title{
CONTINUOUS OBSERVATIONS OF THE CRUSTAL EXTENSION AND TILT IN THE OLD OSAKAYAMA TUNNEL
}

\author{
Izuo OzawA* \\ (Received October 7, 1985; Revised July 17, 1986)
}

\begin{abstract}
Some indications of the possibility of a large earthquake occurrence around Kyoto in the near future are to be found in three kinds of data: auto-correlation curve of destructive earthquake occurrence around Kyoto since the 7th century, annual sums of accelerations caused by felt earthquakes near Kyoto since 1891 and results from precise levelings along a route from Fukuchiyama to Kyoto since 1887. To examine the possibility of occurrence of the said earthquake, data obtained by observations of crustal linear strains and tilts performed at Osakayama since 1951, some observations having been augmented in the period from 1961 to 1970 , were analyzed. Average secular changes were estimated by fitting a typical formula to monthly values from moving averages of 13 months, and deviations of these monthly values from the formula-fitted average secular changes (anomalies) were compared with changes in ground-water level and annual frequency of felt earthquakes. Partial-correlation between the annual means of the observed anomalies in crustal movement at Osakayama and the annual frequency of felt earthquakes is remarkable in most parts of the observations. From the anomalies of crustal deformation, no definite conclusion could be drawn concerning an approaching large earthquake.
\end{abstract}

\section{Introduction}

The Kyoto district is a seismically active area wherein about fifty destructive earthquakes have occurred since the 7th century (TOKYO Astronomical OBSERVATORY, 1986), although there have been no remarkable earthquakes in the vicinity of Kyoto in recent years. It is, therefore, important to investigate the possibility of occurrence of destructive earthquakes in this district on the basis of geotectonical data available at the present stage. In the first part of this paper, statistical data of the destructive earthquakes, annual trends of felt earthquakes and results of precise levelings are critically reviewed, and in the second part, the results from long term observations of crustal movement performed at Osakayama Observatory, Kyoto are analyzed and compared with the frequency of felt earthquakes for the purpose of evaluating the possibility of occurrence of the postulated large earthquake in this district.

* Retired from the Geophysical Institute, Faculty of Science, Kyoto University, Kyoto, Japan. Present address: Fukada-chō 42, Kamitakano, Sakyo-ku, Kyoto, Japan 
2. Trend of Destructive Earthquakes, Felt Earthquakes and Crustal Movement as Determined by Precise Levelings in the Kyoto District

Figure 1 shows the auto-correlation curve of occurrence of destructive earthquakes in Kyoto for the last 1,200 years. The peaks at 100,200, and about 300 years of the curve suggest that destructive earthquakes have occurred at an interval of about 100 years. Moreover, a period of 500 years is also likely, since the peak at 500 years is dominant compared with the peaks mentioned above. According to the

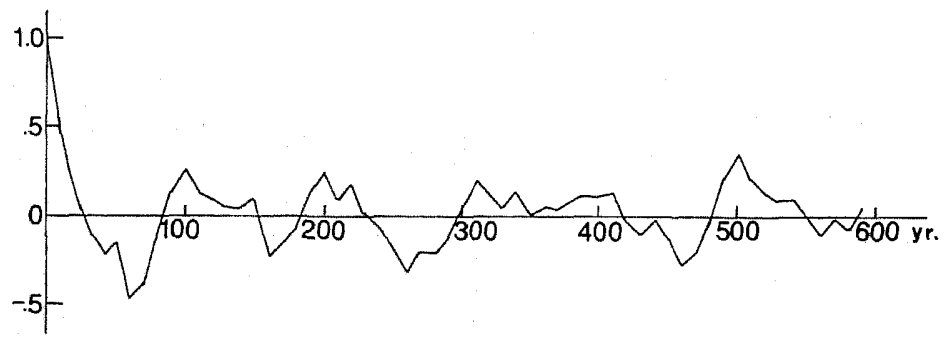

Fig. 1. Auto-correlation curve of the occurrence of destructive earthquakes in Kyoto since the 7 th century.

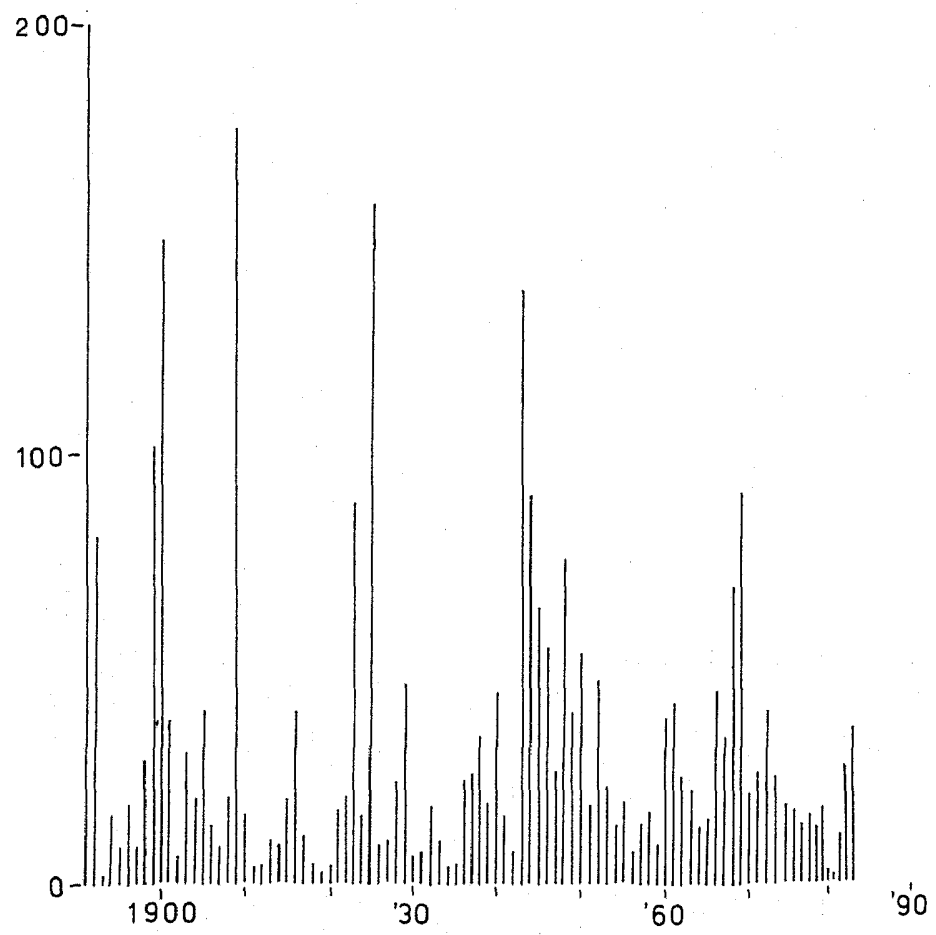

Fig. 2. Annual sums of the acceleration by felt earthquakes in Kyoto. 
relative frequency of earthquakes with magnitudes of 6 and 7 on the Richter scale, it seems reasonable to employ the periods of 100 and 500 years as recurrent cycles of earthquakes with magnitudes of 6 and 7 , respectively.

Figure 2 shows annual sums of accelerations by felt earthquakes in Kyoto since 1891 (Tokyo Astronomical Observatory, 1986; Japan Meteorological AGENCY, 1971, 1971-1985). The sum of these accelerations is calculated by the following formula,

$$
\sum_{I=1}^{5} 0.447 n_{I} 10^{0.5 I}+n_{6} \alpha_{6}+n_{7} \alpha_{7},
$$

where $I$ is the seismic intensity determined by the Japan Meteorological Agency and $n_{I}$ is the annual frequency of earthquakes whose intensity was $I$ in Kyoto. $n_{6}$ and $n_{7}$ are the frequencies of earthquakes of intensities 6 and 7, and $\alpha_{6}$ and $\alpha_{7}$ are the accelerations due to those earthquakes of intensities 6 and 7, respectively. Formula

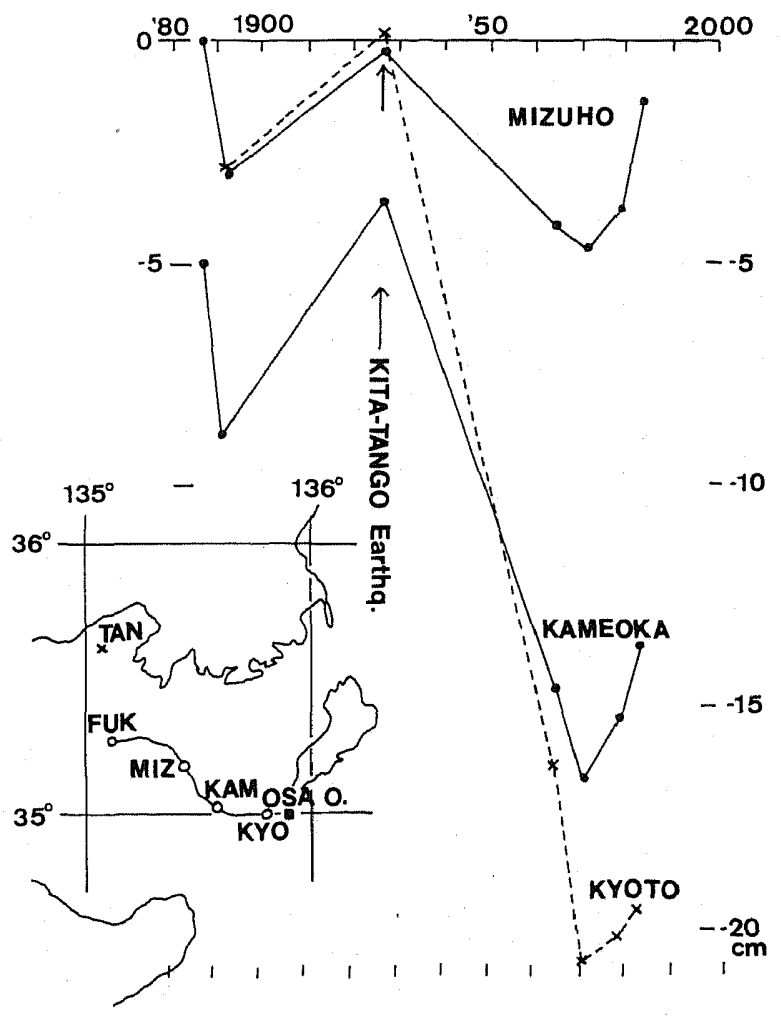

Fig. 3. The vertical movements obtained by precise levelings along the route from Fukuchiyama to Kyoto. The Fukuchiyama district is fixed. TAN, FUK, MIZ, $\mathrm{KAM}, \mathrm{KYO}$, and OSA O. in the figure denote the epicenter of the Great KitaTango earthquake, Fukuchiyama-city, Mizuho-cho, Kameoka-city, Kyotocity and Osakayama Observatory, respectively. 
(1) is derived from Kawasumi's formula, which relates acceleration with seismic intensity, $\log \alpha=(0.5 I-0.6)$ gal. In the derivation of formula (1), mean seismic intensity is assumed to be $(I+0.5)$ instead of $I$ in Kawasumi's formula. The annual sums shown in Fig. 2 have generally been decreasing after the Great Nobi earthquake of 1891. The extrapolation of this trend will reach zero around 2,040. Accordingly, it is probable that earthquake-generating energy is accumulating within the crust while the number of felt earthquakes decreases and the amount of energy will reach a critical value at some time in the future, namely around 2,040, so long as the accumulating rate of tectonic energy is steady during the period concerned.

Precise leveling surveys along a route from Fukuchiyama to Kyoto have been carried out seven times by the Land Survey Department of the Imperial Army and the Geographical Survey Institute since 1887 (GEOGRAPHICAL Survey INSTITUTE, 1969-1980). Results from the surveys are summarized in Fig. 3. The curves in the figure have been obtained by adopting the mean ground level of some bench marks around Fukuchiyama-city as the fixed leveling point. It is apparent from Fig. 3 that the northwestern part of Kyoto had been generally subsiding and has temporarily changed to an upheaval before the great Kita-Tango earthquake of 1927. After the earthquake the Kyoto area continued to subside for many years and changed again to upheave around 1970. This upheaval resembles that before the Kita-Tango earthquake. The Fukuchiyama area is on a stable geological base ground belonging to the Paleozoic system and there is other evidence that the Fukuchiyama area has not been subsiding relative to the northwestern area in Hyogo Prefecture and the coast of the Japan Sea. Moreover, the Kyoto area has been upheaving relative to the northwestern area of Lake Biwa and the coast of Wakasa Bay. Therefore, it seems that Kyoto City and its northwestern area have recently been upheaving.

\section{Crustal Movement Observed at Osakayama and Earthquake Occurrence in the Kyoto Area}

Continuous observations of crustal movement commenced in the old Osakayama Tunnel of the former Tokaido Line in 1947. The tunnel is located at $135^{\circ} 54^{\prime} \mathrm{E}$ and $34^{\circ} 59^{\prime} \mathrm{N}$ (OzAWA, 1974). All instruments are installed at places deeper than $40 \mathrm{~m}$ under the ground in order to avoid meteorological disturbances. Extensometers $\mathrm{R} 1$ and $\mathrm{L} 2$ of $\mathrm{S} 38^{\circ} \mathrm{W}$ component were set around 360 and $520 \mathrm{~m}$ apart from the northeastward entrance of the tunnel, respectively. Extensometers $\mathrm{Cl}$ of the $\mathrm{S} 52^{\circ} \mathrm{E}$ component and $\mathrm{V} 5$ of the vertical component were set at 300 and $270 \mathrm{~m}$ apart from the same entrance, respectively. The $\mathrm{R} 1$ is an extensometer of a low sensitivity type (OzAWA, 1961), and the L2, C1, and V5 are extensometers of a high sensitivity type (OZAWA, 1965).

Reading type water-tube tiltmeters WT1 and WT2 were set around 320 and $70 \mathrm{~m}$, respectively. The WT2 also has been monitored with a continuous recording 


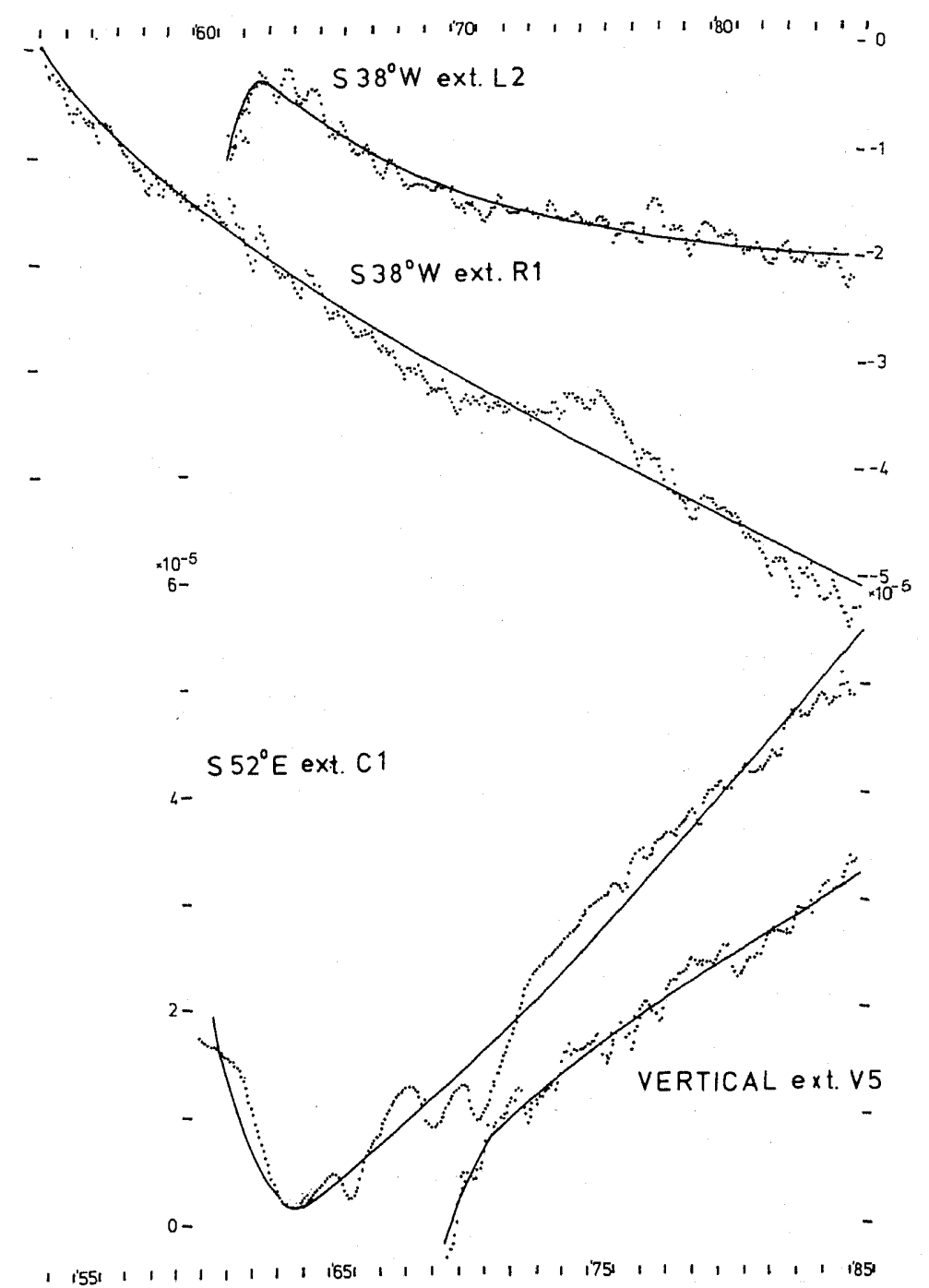

Fig. 4. Observed monthly values of the linear strains and their average secular changes in the azimuths of $S 38^{\circ} \mathrm{W}$ and $\mathrm{S} 52^{\circ} \mathrm{E}$ and in the vertical direction.

device. This continuous record from the WT2 is denoted by WTR in the following (OzAwA, 1967).

Level changes in the ground-water has been observed in a well in which the extensometer of the vertical component V5 is set.

Figure 4 shows the monthly values of the linear strains $\mathrm{R} 1, \mathrm{~L} 2, \mathrm{Cl}$, and V5, and their average secular changes $Y(t)$ which are calculated as follows. A weighted moving average $X(t)$ is calculated from the monthly mean values $M(t)$ by use of the following formula, 


$$
X(t)=\sum_{n=-6}^{6}(7-|n|) M(t+n) / 49,
$$

where $t$ is the number of the month and $n$ is the integer. Next, we express $X(t)$ with a polynomial $Y(t)$ as

$$
Y(t)=a+b / t+c \log t+d t,
$$

where $a, b, c$, and $d$ are constants which are calculated from $X(t)$ by the least squares fitting to $Y(t)$. The polynomials for the strains $\mathrm{R} 1, \mathrm{~L} 2, \mathrm{C} 1$, and V5, tilts WT1, WT2, and WTR, and the level of ground-water GWL are calculated as follows

linear strain $\mathrm{R} 1$ in the $\mathrm{S} 38^{\circ} \mathrm{W}$ :

$$
(1615-1781 / t-670.41 \log t-8.617 t) \times 10^{-8}, \quad \text { since Feb., } 1952,
$$

linear strain $\mathrm{L} 2$ in the $\mathrm{S} 38^{\circ} \mathrm{W}$ :

$$
(-160-372 / t+60.7 \log t-2.94 t) \times 10^{-8}, \text { since Apr., 1961, }
$$

linear strain $\mathrm{C} 1$ in the $\mathrm{S} 52^{\circ} \mathrm{E}$ :

$$
(1664-6449 / t-1154.1 \log t+28.020 t) \times 10^{-8}, \quad \text { since Jan., } 1961,
$$

linear strain V5 in the vertical:

$$
(293-3259 / t-137.01 \log t+11.592 t) \times 10^{-8}, \text { since Sept., } 1969,
$$

tilt WT1 in the $\mathrm{N} 38^{\circ} \mathrm{E}$ :

$$
(1.93+8.473 / t+0.3901 \log t-0.00335 t)^{\prime \prime}, \quad \text { since Jan., } 1961,
$$

tilt WT2 in the $\mathrm{N} 38^{\circ} \mathrm{E}$ :

$$
(-0.0002-0.793 / t+0.203 \log t+0.00134 t)^{\prime \prime}, \quad \text { since Jan., } 1963,
$$

tilt WTR in the $\mathrm{N} 38^{\circ} \mathrm{E}$ :

$$
(-1.18+1.27 / t+0.5391 \log t-0.0826 t)^{\prime \prime}, \quad \text { since July, 1966, }
$$

level of the ground-water GWL:

$$
(-14.45+392.8 / t+14.48 \log t-0.0826 t) \mathrm{cm}, \quad \text { since Sept., } 1961 .
$$

These average secular changes are shown in Figs. 4 and 5.

The change in WTR contains an influence from the instrument caused by the leaking of water in the tube. The last terms proportional to $t$ in these polynomials express mean secular changes per month of the strain or tilt components. The coefficients of R1, L2, WT1, and WT2 are equivalent to $1.0 \times 10^{-6} /$ year, $0.35 \times$ $10^{-6} /$ year, $0.040^{\prime \prime} /$ year, and $0.016^{\prime \prime} /$ year, respectively. These values are usual on orogenic movements in the Tertiary period. The value of $\mathrm{Rl}$ is somewhat larger than usual, and those of L2, WT1 and WT2 are in the normal range of speed of the orogenic movement. It seems that the crustal movement in Osakayama is somewhat fast. 


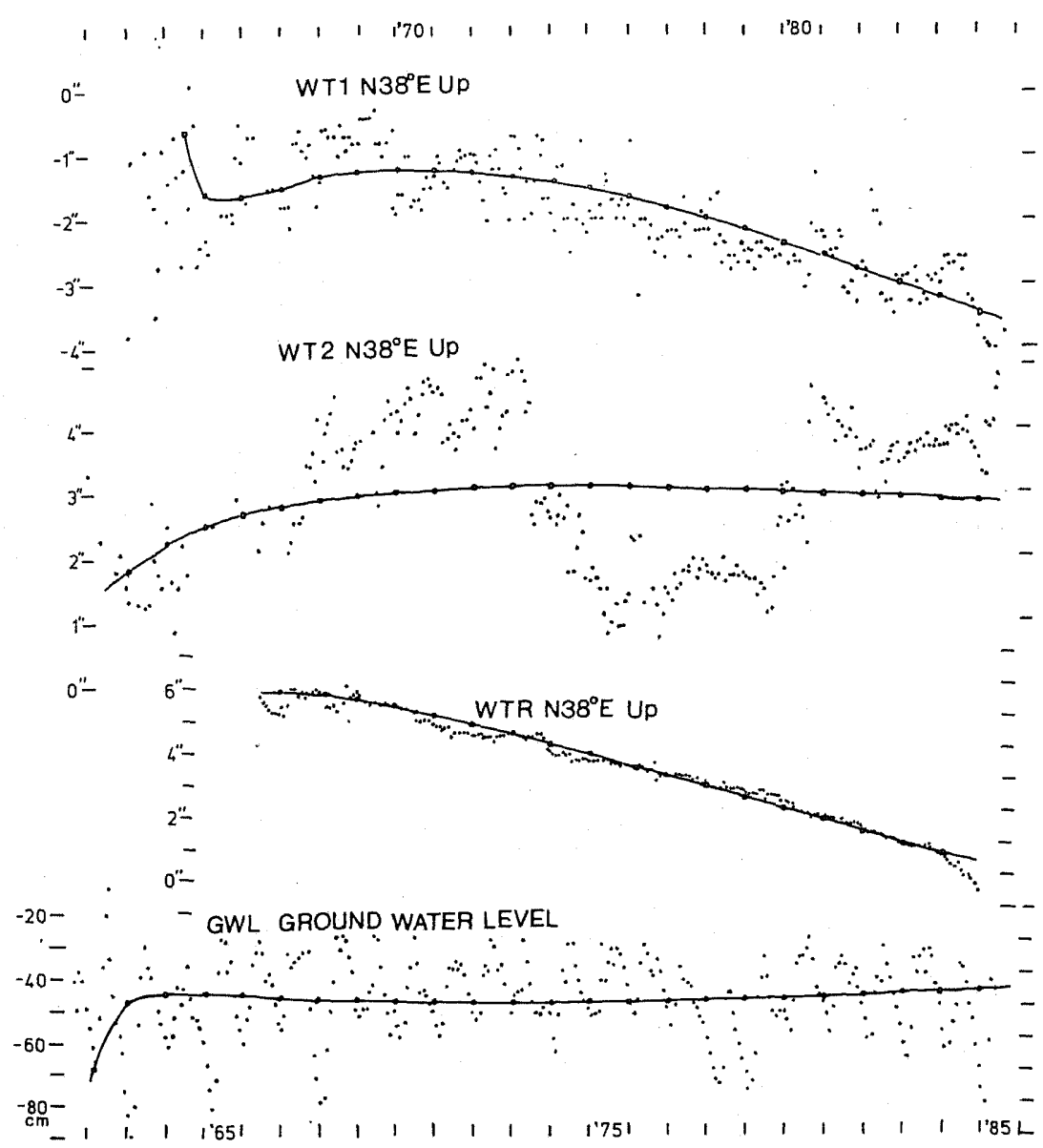

Fig. 5. Observed monthly values of the crustal tilts in the azimuth of $N 38^{\circ} \mathrm{E}$ and the ground-water level in the tunnel, and their average secular changes.

Anomaly $Z(t)$ is calculated from $X(t)$ and $Y(t)$ by

$$
Z(t)=X(t)-Y(t) \text {. }
$$

Monthly values of anomalies of the observations are shown in Figs. 6 and 7 . The lowermost spikes in Fig. 6 are the annual numbers of felt earthquakes in Kyoto. Earthquakes of intensity 4 occurred in 1970 and 1972. Three earthquakes of intensity 3 occurred in 1968, two in 1961, 1969,1979, and 1985, and one in 1962, $1963,1964,1966,1967,1970,1971,1973,1975,1976,1980,1983$, and 1984. It is not easy to discern any significant relationships between these anomalous changes of the observed linear strains or tilts and the occurrence of these earthquakes just by a glance at these figures. 


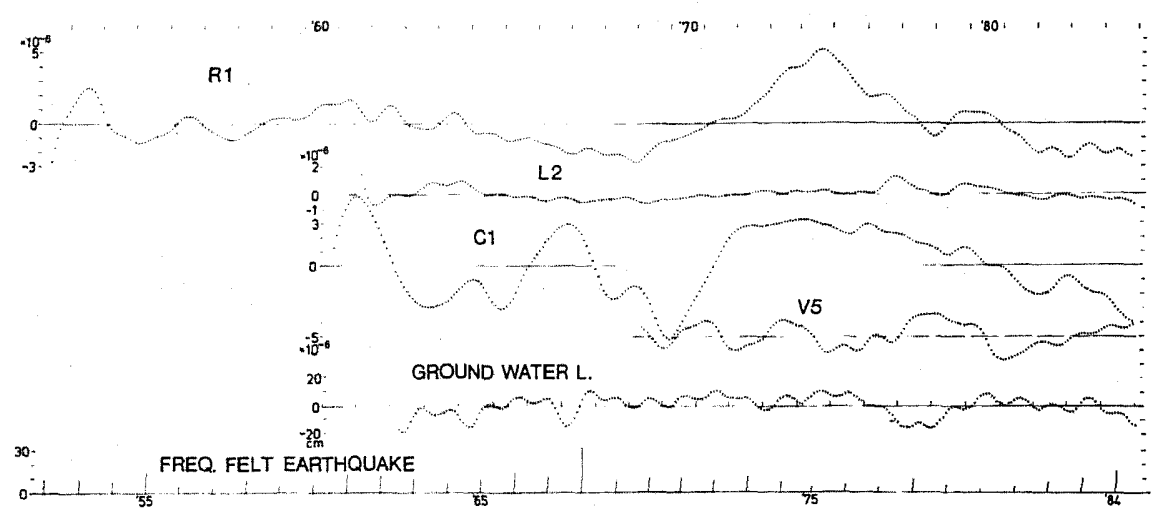

Fig. 6. Monthly anomalies of the linear strains in the azimuths of $S 38^{\circ} \mathrm{W}, \mathrm{R} 1$ and $\mathrm{L} 2$, of $\mathrm{S} 52^{\circ} \mathrm{E}, \mathrm{Cl}$, in the vertical, V5 and of the ground-water level, and the annual frequencies of the felt earthquakes in Kyoto.

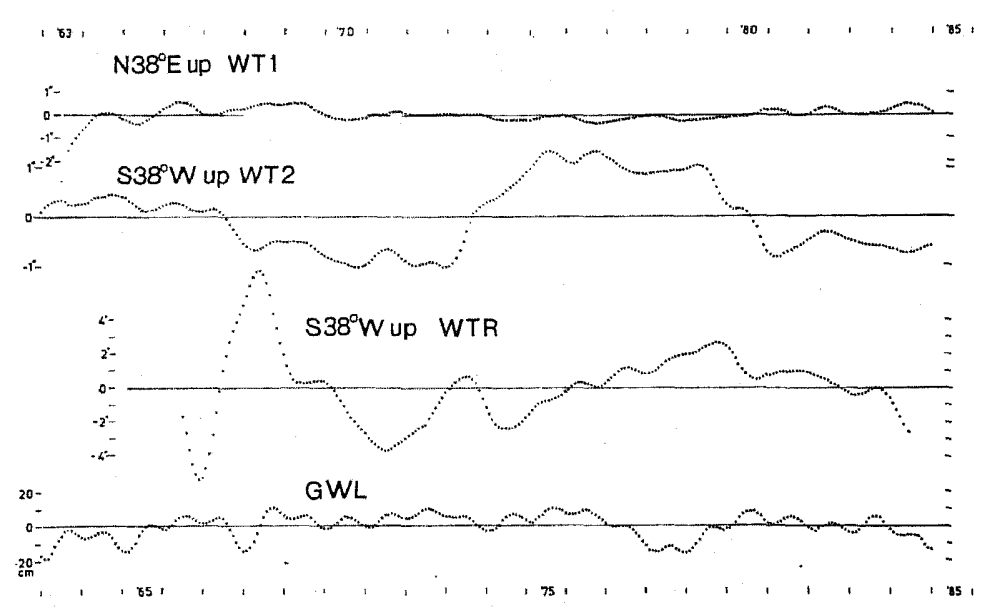

Fig. 7. Monthly anomalies of the tilts in the azimuth of $\mathrm{S} 38^{\circ} \mathrm{W}, \mathrm{WT} 1, \mathrm{WT} 2$, and WTR, and those of the ground-water level GWL.

Now, we designate the time series of annual means of anomalies of the strains and tilts, the frequency of felt earthquakes and the ground-water level as 1,2, and 3, respectively. The correlation coefficient between series 1 and 2 , which we designate as $r_{12}$, is generally influence by series 3 . In order to exclude the influence of series 3 from $r_{12}$, the partial-correlation coefficient $r_{12.3}$ is calculated by the formula,

$$
r_{12 \cdot 3}=-\frac{r_{12}-r_{23} \cdot r_{13}}{\sqrt{\left(1-r_{23}{ }^{2}\right)\left(1-r_{13}{ }^{2}\right)}} .
$$

Thus $r_{12 \cdot 3}$ gives the pure correlation between annual anomalies of the linear strains or tilts and the frequency of felt earthquakes after the influence of the ground-water 
Table 1. Partial-correlation coefficients of annual anomalies of the linear strains and tilts to the frequency of felt earthquakes at Kyoto from which the influence of the ground-water level is excluded, and those of the annual anomaly of the ground-water level in the tunnel from which the influence of the frequency of the felt earthquakes is excluded.

\begin{tabular}{lccr}
\hline $\begin{array}{c}\text { Component of } \\
\text { observation }\end{array}$ & $\begin{array}{c}\text { Analyzed } \\
\text { period }\end{array}$ & $\begin{array}{c}\text { Crustal anomaly vs. } \\
\text { frequency of felt } \\
\text { earthquakes, } r_{12 \cdot 3}\end{array}$ & $\begin{array}{c}\text { Crustal anomaly vs. } \\
\text { ground-water level, } \\
r_{13 \cdot 2}\end{array}$ \\
\hline WT1 & $1962-1984$ & 0.611 & -0.165 \\
|WT1 & $1962-1984$ & 0.495 & 0.141 \\
WTR & $1966-1984$ & 0.265 & 0.311 \\
|WTR| & $1966-1984$ & 0.673 & -0.018 \\
R1 & $1961-1984$ & -0.499 & -0.202 \\
L2 & $1961-1984$ & -0.160 & 0.519 \\
C1 & $1961-1984$ & -0.115 & -0.158 \\
V5 & $1970-1984$ & 0.204 & 0.591 \\
Dilatation 1 & $1970-1984$ & -0.531 & 0.100 \\
(R1+C1+V5) & & & 0.526 \\
Dilatation 2 & $1970-1984$ & -0.542 & \\
(L2+C1+V5) & & & \\
\hline
\end{tabular}

level is eliminated. Similarly, $r_{13.2}$ is the partial-correlation between the linear strains or tilts and the ground-water level after the influence of the frequency of felt earthquakes is excluded. Partial-correlation coefficients $r_{12.3}$ and $r_{13.2}$ have been calculated for these strain and tilt components and are shown in Table 1. It is found from the table that $r_{12.3}$ of $|\mathrm{WT} 1|$ and $|\mathrm{WTR}|$, namely absolute values of WT1 and WTR, and $r_{12.3}$ of R1, dilatations 1 and 2 are significantly large. $r_{13.2}$ of L2, V5 and dilatation 2 are also large. Therefore, it is concluded that the correlations between the annual anomalies of the linear strains or tilts and the frequency of felt earthquakes are fairly large. Since $r_{12.3}$ of dilations are negative and their absolute values are large, the annual frequency of felt earthquakes seems to increase when the crust at Osakayama is compressed. Finally, since the average secular changes and the anomalies in the recent months are not so large as to be specifically noted, no definite conclusion can be drawn at the present stage on the probability of an approaching large earthquake in the near future.

\section{Conclusion}

Some indications of an approaching destructive earthquake are found in the results from precise levelings since 1887, in the trend of annual frequency of felt earthquakes since 1891 and in the recurrence of destructive earthquakes in the last 1,200 years around Kyoto City.

In contrast to the above statement, anomalies of crustal linear strains and tilts derived from continuous observations with extensometers and water-tube tiltmeters 
performed since 1951 do not give evident features to support an approaching large earthquake in the near future.

Through the present study, it was found that the average secular change of the crustal movement at Osakayama is a little fast when compared with usual cases, and that the partial-correlation coefficients between the observed anomalies in the crustal movement and the annual frequencies of felt earthquakes in Kyoto are significantly large when the effect of the ground-water level is compensated for. In conclusion, the continuous observations of crustal movement are reliable and these correlation coefficients may be useful to study and develop methods for the reliable forecasting of earthquakes.

\section{REFERENCES}

Geographical Survey Institute, Annual Reports of the First Order Leveling, Tech. Rep. Geogr. Surv. Inst., 10, 1969; 16, 1973; Special 4, 1975; 24, 1980.

Japan Meteorological Agency, Technical Report of the Japan Meteorological Agency, No. 76, 1971.

Japan Meteorological Agency, The Seismological Bulletins of the Japan Meteorological Agency, January, 1971-December, 1985.

OZAWA, I., Comparative observations of crustal strains by means of wire-type and rod-type extensometers, J. Geod. Soc. Jpn., 7, 1-6, 1961.

OZAWA, I., On the extensometer whose magnifier is the Zöllner suspension type tiltmeter, and the observations of the earth's strain by means of the instruments, Ann. Geofis., 18, 263-278, 1965.

OzAwa, I., On the tidal observation by means of a recording water-tube tiltmeter, J. Geod. Soc. Jpn., 12, 151-156, 1967 (in Japanese).

OZAWA, I., Observations of the crustal movement in the old Osakayama tunnel of the former Tokaido Line, Bull. Seismol. Soc. (Zisin), 2nd Ser., 27, 313-320, 1974 (in Japanese).

Tokyo Astronomical Observatory, Rika-Nenpyo-Chronological Scientific Tables, Maruzen Co., Ltd., Tokyo, 1986. 